\title{
HOW PATERNALISTIC LEADERSHIP ENHANCES PERFORMANCE? EMPIRICAL ANALYSIS OF AFFECTIVE WELLBEING
}

\author{
Muhammad Ilyas Khan \\ Research Scholar, National Defence University, Islamabad \\ ilyas-khancma@gmail.com
}

\author{
Muhammad Zia-ur-Rehman \\ Associate Professor, Dept of Leadership and Management Studies, \\ National Defence University \\ drziaofficial@gmail.com
}

\begin{abstract}
The focus of the article is to investigate the impact of paternalistic leadership performance of middle level managerial employees specifically of universities. For this purpose, we conducted cross sectional and correlational study on middle level managers of different universities of Islamabad and Rawalpindi region. The study population is comprised of 269 randomly selected respondents from different universities. Questionnaires include open ended and close ended questions. That was developed based on existing literature regarding employee performance and Job-related Affective Wellbeing. Employees' performance was measured on task performance and contextual performance. After analysis, results indicate that Paternalistic leadership maintains a significant relationship with employees' performance and paternalistic leadership is also significantly related with job related affective wellbeing. Furthermore, correlation results show that all the three variables have positive and significant association with each other. It is evident that job related affective wellbeing does moderate the relationship amongst paternalistic leadership and employees' performance. At the end the study provides specific gaps for future research.
\end{abstract}

Keywords: paternalistic leadership, employees' performance, JAW, universities

\section{INTRODUCTION}

Leadership research has become one of the crucial areas of focus in the last few decades in order to understand the origin of different leadership theories prevailing in different cultural context. Leaders are directly associated with employees' performance and play major roles to establish the level of employees' participation in organizations. For this purpose, previous studies show different leadership models including ethical leadership and authoritarian leadership (Ozcelik, 2018). Among such models, paternalistic leadership seems well adopted by many countries namely China, India, Pakistan, Turkey and Mexico (Salminen, 2015). Paternalistic leadership (PL) can be considered as one of the leadership styles that is originated from the particular cultural context. Specifically, it does not only focus on characteristics of leadership, yet it further provides analysis based on different dynamic aspects affecting the attitudes and behaviour. The area of interest is to explore the association among leadership style and attitude of employees towards the leader (Avolio, 2009).

There is huge competition in corporate sector around the world and due to that, organizations are much concerned regarding significance of human resource as an important factor of organizations. Based on performance of employees, organizations are in high in competition and more focused to achieve high levels of employees' performance (Liao, 2004). There are also different factors affecting their performance like including but not limited to; satisfaction level of employees, meeting requirements and training sessions (Chang, 2004). Productivity improvement is considered as one of the main issues in current working organizations. Job performance is the main element of productivity and extensive research exists in area of organizational behaviour (OB) and human resource (Schiemann, 2009). Employees' performance is referred to as accomplishment of individuals tasks that have been done by putting efforts and it is connected with a specific environment created to achieve goals (Hellriegel, Karakas, 2010). It is anticipated that individual role and organizational goals are mutually dependent according to organizational psychology (Pfeffer, 1978). Therefore, there is need to focus on factors that are responsible to enhance the performance of employees including 
trainings and satisfaction. Moreover, job related affective wellbeing is also among the important factors need to investigate through employees' performance.

Job related affective wellbeing (JAW) is considered important for the individuals job satisfaction and healthy life. It is one of the most important indicators among different factors of psychological wellbeing (Warr, 1994). Affective wellbeing is basically a multi-dimensional concept that reflects the positive and negative affects based on experience of individuals (Diener,1993). This field is considered to be the most important element of psychological wellbeing due to association related with workplace which includes job satisfaction, income, professional success and job stress. It can be measured to work related wellbeing (Warr, 1990). Positive emotions help people to face unfavourable circumstances and give them strength to flourish out of it. Job satisfaction is the state in which individuals' positive emotions are results from the job experience and is the main issue of working environment. In recent years wellbeing of employees has gain much importance in research as it is main element which contributes to organizational productivity.

\section{REVIEW OF LITERATURE}

In the history of leadership study, mostly researchers have focused on the leadership styles developed in the Western context, not paying much attention to the style of leadership developed in the Chinese context. This paucity of research does not seem to correspond to the increasing globalization and the increasing thirst for knowledge beyond the scope of the Western world. Leadership that involves social influence process always has cultural roots; the cultural fit between the leadership style and the societal ethos is a determinant of organizational success (Chemers, 1997). In this scenario, cultural boundaries are likely to limit the application of Western leadership in non-Western societies such as China. Hofstede (1993) has questioned the universality of Western leadership theories.

\section{Paternalistic Leadership}

Various researchers propose that impracticalities and inapplicability of Western leadership would be barriers to leadership development (Schmidt, 2010). Up to now, social scientists still have a limited understanding of whether and how the Western leadership theories can be applied in China. Therefore, it is essential to comprehend leadership in Asian context. Along with the rapid development of the economy in China and other countries, and progressively imperative role in global economy, an increasing concern in the theory and practice of Chinese management and organizations is drawing considerably enhanced attention. Specifically, some researchers have started to explore the indigenous leadership styles in Chinese organizations using an emic approach. Among the indigenous leadership theories in China, paternalistic leadership (PL) has drawn special attention from researchers since it is one of the most prominent leadership styles found in Chinese organizations. Researchers have hardly ever explored PL despite it being one of the most noteworthy cultural characteristics of Eastern societies (Glinow, 1998). Increasingly, more scholars have contributed to the development of PL theory by systematically conducting empirical research (Farh et al., 2008).

The concepts of paternalism as a management whereas exploratory works on paternalistic leadership gained popularity since last two decades have been credited to Max Weber. Weber (1968) differentiated three kinds of genuine dominance such as charismatic, traditional and bureaucratic. Researchers testify that paternalism not only fulfils today's psychological needs of the workforce but it also meets their materialistic needs as well. In addition to this they both also claim that workers must consider paternalism to be a practical and sustainable option in their strategic repertoires. Paternalism specifies that key staff of the organization must show keen concern in the workers' offthe-job life style and should promote workers' personal welfare (Erez, et al, 2007).

\section{The Emergence and Development of Paternalistic Leadership Theory}

Weber (1968) was of the opinion that control has a vital influence in human aggregate activity. He depicted paternalism as quite possibly the most rudimentary sorts of customary mastery and characterized PL as the framework or rules of overseeing and controlling the nation or different associations, very much like the manner in which youngsters are treated by their dad. 'In the Weberian point of view, paternalism is one of a few univocal types of legitimized authority' and a 'segment of administrative technique' (Padavic, 1994). 
Research done on paternalism arising out of Asia is in a contrary position to Weber's view of simply the authoritarian style. It is asserted that paternalistic leaders offer help, insurance and care to their subordinates (Redding et al., 1994). Following one year's perception and many meetings in a huge business in Taiwan, Silin (1976) tracked down that the initiative ideas and conduct styles of entrepreneurs and supervisors in Taiwan were enormously not quite the same as those in the West. The distinctions were shown through different practices like instructive initiative, moral administration, brought together position, keeping social separation with subordinates, keeping aims vague defined and executing control strategies. By calling attention to the noticeable exceptional authority highlights in Chinese privately-run company, Silin established the framework for the idea of paternalistic leadership.

Following Silin's (1976) research, through top to bottom meetings with proprietor/directors, Redding (1990) recognized a particular brand of financial culture marked 'Chinese free enterprise', in which paternalism is a key component. His exploration spread over a 20-year time span, and the examples incorporated the family firms in Hong Kong, Taiwan and Southeast Asia. He called attention to that man centric is a significant element of Chinese undertakings, seen that Chinese social orders have a solid tradition of personalism, and noted one extra segment - considerate administration. He characterized generosity as 'paternalistic consideration and concern' and 'affectability to subordinates' feelings', and recommended that altruism is executed via favour.

Previous studies have identified two major leadership styles in the domain of PL, namely authoritarianism and benevolence (Aycan, 2006). Moreover, Farh and Cheng (2000) proposed a third paternalistic component - morality. They defined PL as a style that combines strong discipline and authority with fatherly benevolence and moral integrity couched in a personality atmosphere. Cheng et al (2000) established a three- dimensional paternalistic leadership scale with 42 items. The model clearly identified the basic content domain of PL and built a reliable and valid measurement scale with 26 items subsumed under three dimensions.

\section{The Cultural Roots of Paternalistic Leadership}

Culture assumes an essential part in initiative viability since it decides the qualities, convictions and inclinations of hierarchical individuals (Jiang and Cheng, 2008). PL has its foundations in the Chinese customary culture described by Confucianism and legalism. Dictator administration originates from the social custom of Confucianism and legalism, which features the centrality of the upward connection among bosses and devotees (Farh, 2000). Confucian philosophies incline Chinese pioneers to go about as the parent of the gathering or association, and to rehearse tyrant control (Hui, 1996). Besides, tyrant administration is additionally supported by legalism, which stresses the ideas of control and political control useful during the long history of magnificent China. Thus, impacted by China's man centric practice, dictator pioneers kept up with solid power and tight command over subordinates, and subordinates were committed to be devoted. Big-hearted initiative begins from the Confucian ideal of the five cardinal connections and the standard of correspondence (Cheng et al., 2004). Confucianism advocates that a dad ought to be nurturant and kind to his youngsters and that the kids should extend regard and obedient devotion to their dad. In like manner, big-hearted directors play out their jobs by giving direction, assurance and care to their subordinates; the subordinates are in this way obliged and expected to respond by showing appreciation and reimbursement to their chief.

Moral initiative might be followed to the social practice of Confucianism (Cheng et al., 2004), under which exclusive requirements of conduct are normal and appreciated in pioneers. Confucius accepted that the best type of the executives' administration was driving by idealistic execution and by upright model. A pioneer ought to set up his/her power through exhibiting model profound quality (Cheng, 2000). Consequently, subordinates are probably going to regard and relate to the pioneers with high profound quality and honesty and attempt to emulate those characteristics (Yang, 1957).

\section{Mapping the Domain of Paternalistic Leadership}

The three explicit components of PL anticipate the mental reactions of workers: explicitly, tyranny is required to bring about subordinates' consistence and reliance, pioneers' altruism is relied upon to build subordinates' appreciation and response, though pioneers' profound quality is relied upon to advance subordinates' regard and distinguishing proof. Researchers found that consistence was 
uncorrelated with dictator authority, yet altogether corresponded with moral initiative and generous administration (Cheng et al. (2004). Others found that while consistence was fundamentally connected with dictator initiative, it was corresponded all the more emphatically with generous authority and good administration (Farh et al. 2006). They further found that dread of the pioneer intercedes the impact of dictator initiative on consistence. It was discovered that appreciation and reimbursement was emphatically decidedly connected with consideration, and less firmly corresponded with moral administration (Farh et al., 2006). Moral administration was emphatically connected with the subordinate's mental reaction of ID with the pioneer (Farh et al., 2006), and it had the biggest beta load to anticipate ID with the pioneer than generous and dictator authority (Farh et al., 2006). The earlier examination demonstrated the chance of covering of the mental components and showed that generous initiative had the main impact on subordinate appreciation and reimbursement to the pioneer, while moral authority had the biggest impact on subordinates' consistence and ID with the pioneer.

\section{Employee Performance}

Employee performance refers to a person's ability to do a work according to set accuracy, completeness, cost, and speed standards (Sultan et al, 2012). The term Performance means the ultimate results arrived from the employees' accomplishments which are foundation of the abilities together with the knowledge of the employees. In organisational contexts, employee performance refers to the sum of all employees' aptitudes, hard work, and capabilities that contributed to the productivity of the organization, and also achievement of the goals of the organization. Researchers described that enhanced organisational performance is the result of goal-oriented activities, but improved employee performance necessitates more and more efforts (Ellinger et al, 2003). One of the most essential factors in determining a company's success is employee performance. Learning about the environment of the organisations plays a critical task in increasing the performance of the employees by providing training chances and opportunities for development of skills (Gitongu et al, 2016). In addition to that, the standards of management which evaluates the performance of the employees are crucial and important in improving the performance of the employees because they demonstrate actual outcomes and performance together with how it has been compared with the benchmarks. But if there are differences which are discovered, the standard discussed support to bring the level of the desired outputs back on track and to achieve the desired objectives (Mackay et al, 2004). The performance of employees is also affected by how satisfied they are with their work on an internal level. The motivation of employees is high for performance so that they are able to attain organisational targets if the employees are content for the jobs and their organization (Harter et al, 2002).

Why do certain businesses outperform others and are named the year's most favoured employer? The use of attractive reward schemes to motivate employees toward meaningful job involvement has been explored in previous research. At the same time, there is enough empirical proof which suggests for the monetary incentives that is having diverse effects, and that might not be as important as previously thought for improving employee performance (Shaw, 2014).

All these are owing to the varying characteristics of tasks in the time of post globalization era, as well as the rise of knowledge workers, which have resisted traditional notions of individual work performance.

The question that emerges here is what other behavioural aspects influence boosting employe es' performance if financial benefits do not match with the performance and efforts of the employees. Simultaneously as organizational requirements change, the ability to adapt is becoming a more relevant metric to absorb in performance.

The term performance is a multifaceted term, and the different aspects of performance, i.e., interactions of behaviour, can be eminent from the intended outcome on a fundamental level (Roe, 1999). The phrase "behaviour" refers the actions of the people which are important for completing different tasks, whereas the terminology of "outcome" means the result of the job behaviour of individuals. While in a workplace, it appears that behavioural engagement and expected outcomes are linked (Motowidlo, 1993), however, there isn't yet a complete overlap between the two categories because the expected outcome is impacted more by elements like motivation and cognitive abilities than by the behavioural part. Job categorical behaviours, which include core job obligations specified as part of the job description, are included in task performance. Task performance necessitates a 
higher level of the ability of cognition, which is first and foremost eased by the knowledge about the task (the technical knowledge which is necessary for tasks or values to guarantee the performance of job and the aptitude to perform different and multiple assignments), skills about the task, and knowledge about the task (appliance of technical information to complete responsibilities successfully without the help of supervisors). As a result, the capacity to do the work and prior experience are the most important antecedents of task performance. Task performance is a contractual agreement between a manager and a subordinate to complete a given task in an organisational context. Technical-administrative task performance and leadership task performance are the two types of tasks entrusted to you. The term technical-administrative task performance involves the required performance of job that includes scheduling, organising, and managing daily tasks by using the technical abilities, judgement of business, together with other skills. Targets of strategic goals, keeping appropriate performance standards, stimulating and directing assistants to accomplish the tasks by means of encouragement, praise, and productive criticism are all the different methods that measure the performance by the leadership (Brush, 1993). It is defined that the term job performance in the context of the performance of task as the efficiency with which the occupants of the job complete their allocated duties, which results in the realisation of the vision of the organization while appropriately gratifying the organisation and the individuals involved (Werner, 1994). The scholars have consolidated past task performance arguments by connecting them to organisational formality. The exhibited expertise and behaviour that manipulates the nonstop creation of commodities or services, or any other type of activity so as to offers indirect assistance to any organization's basic technological operations, is defined as a reward.

In today's businesses, increasing productivity is a major concern. From the vast literature on the field of organisational behaviour (OB) and human resource development (HR), productivity via work performance is a highly investigated domain (Schiemann, 2009). The performance of job, as measured by the evaluation of performance and administration, is a component which is very important of good HR supervision and a popular developmental interference in the HR range (Snell et al., 2007). The word "employee performance" indicates to a person's task accomplishments by putting the necessary efforts needed to perform the job, obtaining meaningful employment, an active profile, and compassionate co-workers/employers (Karakas, 2010).

An excellent system of management of employee performance is essential for a company organisation for the purpose to completely utilise HR and enhance organisational achievement. The goals based on performance should be harmonized with the policies of the organisation policies so that the entire procedure shifts from event-driven to strategic and surrounded by people (Pradhan, 2014).

Adaptive performance refers to an individual's capacity to acclimate and offer essential support to the job profile in a dynamic work environment (Hesketh, 1999). Employees tend to adapt the manners and behaviour for the diverse requirements of the positions of job once they achieve a definite level of expertise in their given activities, according to previous studies. (Huang et al., 2014). The ability of employees' to effectively deal with changeable work situations, for example technology transformations, the change in employees' primary assignment of job, organisational reorganization, and so on, is required to the effective adaptive performance (Baard et al., 2014). As a result of the development of several new professions due to technology advancement, employees must participate in new learning and become more adaptive to changes in a timely manner (Griffin et al., 2010). The Employees must also alter their interpersonal behaviour to operate efficiently with a group of varied peers and assistants in such changing situations (Griffin et al., 2007). Others pointed out that adaptability and pro-activeness in one's employment position are crucial in coping with uncertain business scenarios, while job competency can help with task performance.

For the purpose of establishing a better place of work, attempts that have been made for determining the importance of those components which are non-job for performance together with the task and compliance (Ones et al., 2000). Components of non-job term such as organisational attachment behaviour or contextual performance (Organ et al., 1983) have been referred to by industrial psychologists as non-job components benefit employers intangibly. Individuals in a work setting exhibit appropriate performance, a type of behaviour related to prosocial. Employees are expected to behave in specific ways, although these expectations aren't specified directly in their job descriptions. These forms of hidden expectations are referred to as prosocial behaviour or extra role behaviour (Motowidlo, 1986). It seems identified that it as a type of behaviour that is (i) carried out 
by an organization's member, (ii) is intended at a person, a group, or an organisation with whom the member interacts while performing his or her job, and (iii) is carried out with the intention of assisting the individual, group, or organisation to which it is aimed to improve.

\section{Organizational Commitment}

One of the important factors in obtaining competitive performance is organisational commitment. Organizational commitment (Morrow, 1993). The concept is described that it as a multidimensional construct that can be used to predict outcomes like as performance, turnover, absenteeism, tenure, and organisational goals. As a result of its documented association with work-related constructs such as absenteeism, turnover, job satisfaction, job involvement, and leader-subordinate relations, organisational commitment has emerged as an essential construct in organisational research (Meyer et al., 1993). Employees are more committed to staying with their present employers when they believe they can grow and learn with them, according to research (Opkara, 2004). Furthermore, committed and contented employees are usually great performers who contribute to the productivity of the firm (Samad, 2007).

The concept "commitment" is defined as a partisan, emotive connection to an organization's aims and values, one's function in respect to those goals and values, and to the organisation for its own sake, independent of its strictly instrumental value (Buchanan (1974). Three parts make up the commitment:

Identification entails adopting the organization's aims and ideals as one's own; Involvement entails Immersion or absorption in one's own activity on a psychological level, Professional function; \& Loyalty is defined as a strong attachment to and commitment to an organisation. The term "organisational commitment" can be defined in a variety of ways.

O'Reilly (2001) backs this up by defining organisational commitment as an individual's psychological link to the organisation, which includes feelings of job involvement, loyalty, and belief in the organization's principles. To put it another way, organisational assurance is well-defined as the degree to which an individual identifies with the aims of the group's many stakeholders. Thus, organisational commitment can be defined as Affective responses or attitudes that link a worker to his or her employer. It consists of three different types of stages: the first is compliance, the second is identification, and the third is internalisation, all these indicates the acceptance of the influence of others by the person in order to obtain from others, something in order to sustain a gratifying and selfdefining association, and the person discovers the organization's values to be fundamentally racial. Organizational commitment, described by Chin and Sheehan (2004), is a construct having multi dimensionality that can be generalised to the managers of Malaysia, as evidenced by the 500 Malaysian managers study, supported by Allen et al.,1991)

Expert responsibility has been conceptualized incredibly, e.g., as displayed by Men (2015), it is the quickening viewpoint held by the specialists toward the affiliation and its qualities. The degree of expert execution is completely obliged by the degree of risk an agent has toward their affiliation and its qualities (Selvarasu et al, 2014). A pulled in ace thinks about business setting and works with partners to moreover foster execution inside the work to help the alliance (Ologbo et al., 2013). As per Men (2015), responsibility is portrayed by energy, support, affiliation, adequacy, life, commitment, power and a positive state which are depicted as driving forces for master execution. As shown by Shantz, Alfes, District, and Soane, (2013), related with specialists have a raising perspective and have business related perspective portrayed by life, responsibility, and assimilation and these make the experts mentally present at work, which restricts their likelihood to oversee business related stirred up assumptions and mistakes. Gichohi (2014) clarifies that there is palatable association between master responsibility and expert execution through expanded risk and this is on the grounds that, drawn in workers experience mind boggling appraisals which encourages their reasoning, driving them to wind up being more attentive and ingested in their work. (Shantz et al., 2013).

\section{Job Related Affective Wellbeing (JAW)}

The rising necessity to measure JAW with short scales has been a crucial trend in recent years in work and organisational research. This appears to have been encouraged in two research environments in particular. Research scholars described that the growing popularity of repeated measurements, diarybased techniques for evaluating intra-individual JAW changes entails regularly engaging the concerned people to rate their feelings across time. Second, since JAW predicts very strongly the 
outcomes of studies in organisation, they minutely discussed that the scales of JAW are routinely used as an integral part of scales that are used in group for the assessment of individual as well as workplace features (McGonagle et al., 2015). These features and characteristics are measured by other researchers in the form of repeated-measures, as well as the measures independently, and also crosslevel and the need of short JAW measures to researchers in these situations are to prevent the regular memory and tasks which are disrupting, and also for the avoidance of aggravating points of the participants where the procedure of response are forced (Fisher, 2016). This concept holds true in practise because the people and participants involved can be expected to perform the tasks and duties on a regular basis (Russell et al., 2017). A considerable number of existing theoretical models that emphasis on folks' emotional work experiences in a practical setting include catching the causative and proximal factors on affective experiences in a swift, unambiguous, and time-bound manner (Ouweneel et al., 2012).

In recent years, there has been a lot of discussion and research around the JAW's structure and measurement. Although some theories contend that JAW is denoted by two distinctive extents of positive and negative affect, each of which includes terms with varying levels of activation, others contend that JAW is symbolized by a single dimension of positive and negative affect (Tellegen et al. 1999), Some of the others argue that a circumplex model is preferable, in which specific phrases are distinguished by two orthogonal axes of heavy tone and activation (Russell et al. 1999). In both cases, affect is divided into two parts: one related to the hedonic tone or valence of the emotion (e.g., how positive or negative it is), and the other related to the emotion's activation or intensity, (for example, whether it corresponds to a high or low level of arousal) (Warr et al. 2003). Measurements must essentially ensure a fine blend of positive and negative hedonic tone (valence), as well as varying levels of activity, in order to accurately represent affect.

Customarily affect is studied on a trait-based level, as well as a construct that differs amid people (Beal et al. 2005). At the time of one-time JAW measurements, long form scales were apposite and selected due to largely greater reliability and validity coefficients associated with longer measures (Watson et al. 1999). There are several well-known questionnaires for assessing JAW (Van et al., 1988), but they can be too long to use in modern organisational study designs that require brevity. Furthermore, several well-known JAW measures maintain shortcoming in their psychometric construction. For example, the most commonly used JAW measure is the positive and negative affect schedule (PANAS) (Diener et al., 2010). It was developed by Watson et al. (1988), but after criticism that it failed to measure low activation terms and other important impact components, it was revised to include a broader range of terms. This updated form, the 60-item PANAS-X, takes about 10 minutes to complete (Watson et al. 1999), demonstrating how construct validity is sacrificed for concision. Other well-being surveys have struggled with a similar problem as to how to ensure that the measure systematically samples impact without being exorbitantly long (Van et al., 2000) - and are thus inappropriate for repeated-measures or multiple-scale data collection (Ohly et al. 2010).

\section{Theoretical Framework}

Following the previous discussion, and the proposed hypotheses, the research model (Conceptual Framework) is presented as follows.

Figure -1 . The conceptual framework of the study

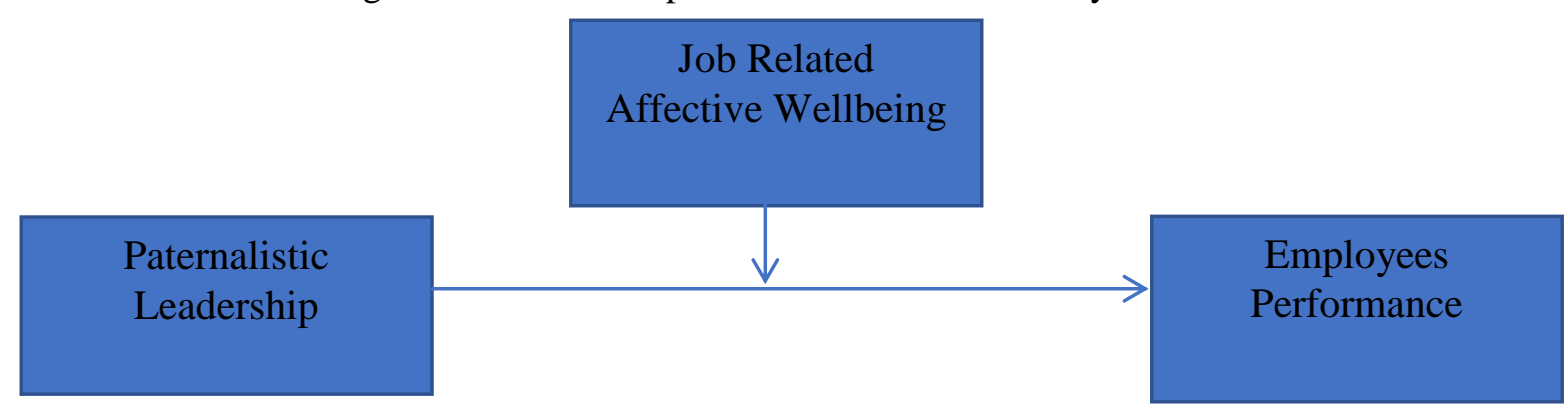

The following hypotheses have been put forth:

H1: There is a positive impact of paternalistic leadership on employees' performance. 
$\mathrm{H} 2$ : Job related affective wellbeing moderate the relationship of paternalistic leadership and employees' performance.

\section{METHODS AND MEASURES}

Structured questionnaire is developed on a 5-point Likert scale (measurement scale by sheer 2010). Questionnaires include open ended questions and close ended questions. Previously scholars usually target large audience which includes above 30 respondents (citation). Open ended questionnaires provide freedom to respondents to give opinion as per their capability, but this approach was not considered valid. Hence, the study includes close ended questionnaire as it analyses the role of job affective wellbeing. Questionnaire is developed based on existing literature regarding employee performance and job-related effective wellbeing. Employees' performance was measured on task performance and contextual performance. The unit of analysis of the study is managerial or director level employees of universities. Middle level directors having supervisory role are selected across different universities. They filled out an online Likert scale questionnaire consisting three parts, paternalistic leadership, employees' efficiency and job-related affective wellbeing

\section{Population and Sampling}

The sample was selected based on population. Overall population expected to be approx. 500, however due to COVID-19 it was not possible to collect from all the respondents. Therefore, a sample of 310 floated based on the formula was selected. However, after a long time, only 284 were received back. Out of 284, discarded 15 and finally 269 were usable questionnaire and analysed accordingly. The response rate found was $86 \%$ as the total 269 were usable questionnaire out of the floated 310 questionnaires.

\section{Descriptive Statistics}

Data analysis was carried out using various statistical tests in order to check the proposed hypotheses. For that, first we carried out the descriptive tests to see the bases of the data and then we carried out inferential tests. More prominent tests include correction analysis and regression analysis.

Table 1

Descriptive Statistics Showing Age Based Information

\begin{tabular}{llcccc}
\hline & & GENDER & AGE & EXPERIENCE & EDUCATION \\
\hline $\mathrm{N}$ & Valid & 269 & 269 & 269 & 269 \\
& Missing & 0 & 0 & 0 & 0 \\
\hline
\end{tabular}

To know the probability of unknown individual as well as extraordinary dissimilarity in the data, descriptive analysis was carried out. Total of 269 cases were observed in the study. The results of the data confirm accuracy of the data of the study through distribution of frequency, mean and standard deviation.

Table -2

Descriptive Statistics Showing Gender Based Information

\begin{tabular}{llcrcc}
\hline & & & & \multicolumn{2}{c}{ Cumulative } \\
\hline Valid & Male & 161 & 59.9 & 59.9 & 59.9 \\
& Female & 108 & 40.1 & 40.1 & 100.0 \\
& Total & 269 & 100.0 & 100.0 & \\
\hline
\end{tabular}

The descriptive statistics across gender demonstrate that the frequency of men is 161 along with respective percentage 59.9 and frequency of women participants is 108 along with percentage 40.1. It shows the higher frequency of male participants for the study. 
Table -3

Descriptive Statistics Showing Age Based Information

\begin{tabular}{llcccc}
\hline & & & & \multicolumn{2}{c}{ Cumulative } \\
\hline Valid & Less than 20 Years & 2 & .7 & .7 & .7 \\
& $20-30$ & 36 & 13.4 & 13.4 & 14.1 \\
$31-40$ & 157 & 58.4 & 58.4 & 72.5 \\
$41-50$ & 51 & 19.0 & 19.0 & 91.4 \\
Above 50 & 23 & 8.6 & 8.6 & 100.0 \\
Total & 269 & 100.0 & 100.0 & \\
\hline
\end{tabular}

The descriptive statistics for age demonstrated that .7 percent of the participants of this study are 20 years old, 13 percent participants are between 21-30 years, while around 58 percent people are between 31-40 years of age, around 19\% are 41-50 years of age, and around 8\% participants are above 50 years of age. However, majority age bracket is in the third and fourth options.

Table -4

Descriptive Statistics Showing Experience Based Information

\begin{tabular}{llcccc}
\hline & & & & Cumulative \\
& & Frequency & Percent & Valid Percent & Percent \\
\hline Valid & 5 Years or less & 42 & 15.6 & 15.6 & 15.6 \\
& $6-10$ & 82 & 30.5 & 30.5 & 46.1 \\
& $11-15$ & 76 & 28.3 & 28.3 & 74.3 \\
& 16 and Above & 69 & 25.7 & 25.7 & 100.0 \\
& Total & 269 & 100.0 & 100.0 & \\
\hline
\end{tabular}

The descriptive statistics for experience of the respondents of questionnaire ranges from 5 Years or Less to 16 years and above. The study expresses the frequency of respondents with the job experience of 5 Years or Less as 42 with $15.6 \%$. However, next bracket of experience is of 6-10 years which exhibits frequency as 82 with $30.5 \%$. Likewise, the next bracket of experience is of 11 15 years which displays frequency as 76 with $28.3 \%$, and 16 years and above are 69 in number with $25.7 \%$

Table -5

Descriptive Statistics Showing Education Based Information

\begin{tabular}{llcccc}
\hline & & & & Cumulative \\
Valid & Higher Secondary & 21 & 7.8 & 7.8 & 7.8 \\
& Certificate & 72 & 26.8 & 26.8 & 34.6 \\
& Bachelors & 161 & 59.9 & 59.9 & 94.4 \\
& Masters & 15 & 5.6 & 5.6 & 100.0 \\
& Doctorate or above & 269 & 100.0 & 100.0 & \\
Total & & & & \\
\hline
\end{tabular}

The descriptive statistics for education of respondents of the questionnaire range from Higher Secondary Certificate (HSSC) to Doctorate or above. The study reveals that most of the choices are of the masters level demonstrating the total number as 161 out of 269 with the percentage of $59.9 \%$. Moreover, next lower level of education of the respondents is bachelor as of 72 in number depicting $26.8 \%$. Likewise, respondents of Higher Secondary Certificate (HSSC) level are 21 in number with $7.8 \%$ and Doctorate or above level are 15 in number with $5.6 \%$. 
Table -6

Reliability Statistics

\begin{tabular}{lcc}
\hline Construct & Cronbach's Alpha & N of Items \\
\hline Paternalistic & .672 & 12 \\
Leadership & & \\
Employees & .889 & 21 \\
Performance & .928 & 10 \\
Job-related AW & .928 . & \\
\hline
\end{tabular}

The table of results of Cronbach's alpha exhibits the reliability of all the three instruments that have been in practice in order to measure the variable of the research. It has been learnt that all the three variables of the study are reliable and valid. Paternalistic Leadership maintains .92 Cronbach's alpha value with the total number of instruments as 10 . While the values of Cronbach's alpha for Employees' performance and Job-related affective wellbeing are .88 and .67 respectively, which further elucidates and confirms that all the scales are reliable.

\section{CORRELATION ANALYSIS}

Table -7

Correlation Analysis

\begin{tabular}{ccc}
\hline Paternalistic & Employees & \\
Leadership & Performance & Job Related Affective Wellbeing \\
\hline
\end{tabular}

Paternalistic Leadership

1

Employees Performance

Job Related Affective Wellbeing

$$
.136^{*} \quad .337^{* *}
$$

1

**. Correlation is significant at the 0.01 level (2-tailed).

*. Correlation is significant at the 0.05 level (2-tailed).

The result in table demonstrates that Paternalistic leadership maintains a significant relationship with dependent variable Employees' performance. Likewise, Paternalistic leadership is also significantly related with Job related effective wellbeing. Moreover, employee's performance is also related with job related effective wellbeing i.e. all the three variables are positively and are significantly correlated with each other. But this correlation does not explain relationship of the variables. Hence to determine the positive and negative relationship, it is necessary to run regression analysis.

Table -8

Model Summary

\begin{tabular}{cccccc}
\hline Model & $\mathrm{R}$ & R Square & Adjusted R Square & $\begin{array}{c}\text { Std. Error of } \\
\text { the Estimate }\end{array}$ & Sig \\
\hline 1 & $.509^{\mathrm{a}}$ & .259 & .253 & .41743 & .000 \\
2 & $.510^{\mathrm{b}}$ & .260 & .252 & .41783 & .000 \\
\hline
\end{tabular}

a. Predictors: (Constant), Job_Related_AW, Paternalistic_Leadership

b. Predictors: (Constant), Job_Related_AW, Paternalistic_Leadership, Inter_Term

The results in above table shows job related affective wellbeing and paternalistic leadership predicted employee's performance. Adjusted R square is .259 for model 1 and .260 for model 2. Both the models are significant on .000 levels. 
ANOVA

ANOVA (Variation Analysis) is an analytical and mathematical instrument which is used to determine whether the means of two or more groups are expressively dissimilar to one another. In addition, it segregates perceived aggregate variability (found inside a data set) into two categories: systematic elements and random elements. However, systematic elements maintain a statistical impact on a particular data set, while random element does not maintain any such impact. In a regression study, analysts apply the ANOVA test to assess the effect on the dependent variable by the independent variables. The one-way ANOVA is applied to three or more data groups, to obtain data about the relationship between independent and dependent variables.

\begin{tabular}{llrrrrr}
\multicolumn{7}{c}{ Table $-9^{\text {ANOVA }}{ }^{\mathrm{a}}$} \\
\hline Model & & Sum of Squares & df & Mean Square & F & \multicolumn{1}{c}{ Sig. } \\
\hline 1 & Regression & 16.200 & 2 & 8.100 & 46.486 & $.000^{\text {b }}$ \\
& Residual & 46.349 & 266 & .174 & & \\
& Total & 62.549 & 268 & & & \\
2 & Regression & 16.284 & 3 & 5.428 & 31.092 & $.000^{\text {c }}$ \\
& Residual & 46.265 & 265 & .175 & & \\
& Total & 62.549 & 268 & & & \\
\hline
\end{tabular}

a. Dependent Variable: Employees_Performance

b. Predictors: (Constant), Job_Related_AW, Paternalistic_Leadership

c. Predictors: (Constant), Job_Related_AW, Paternalistic_Leadership, Inter_Term

\section{Coefficients $^{\mathrm{a}}$}

Table -10

Coefficients $^{\mathrm{a}}$

\begin{tabular}{llccccc}
\hline & & \multicolumn{2}{c}{ Unstandardized } & \multicolumn{2}{c}{$\begin{array}{c}\text { Standardized } \\
\text { Coefficients }\end{array}$} & $\begin{array}{c}\text { Coefficients } \\
\text { Model }\end{array}$ \\
& & $\mathrm{B}$ & Std. Error & Beta & $\mathrm{t}$ & Sig. \\
\hline 1 & (Constant) & 1.529 & .249 & & 6.142 & .000 \\
& Paternalistic_Leadership & .423 & .059 & .385 & 7.219 & .000 \\
& Job_Related_AW & .220 & .041 & .285 & 5.351 & .000 \\
2 & (Constant) & 1.567 & .255 & & 6.144 & .000 \\
& Paternalistic_Leadership & .408 & .062 & .371 & 6.564 & .000 \\
& Job_Related_AW & .191 & .059 & .247 & 3.244 & .001 \\
& Inter_Term & .218 & .031 & .306 & 4.695 & .000 \\
\hline
\end{tabular}

a. Dependent Variable: Employees_Performance

The results in table above reveal that Paternalistic leadership and job-related affective wellbeing have a significant influence on employees' performance $(\beta=.385, \mathrm{p}<.059)$, and $(\beta=.285$, $\mathrm{p}<.041$ respectively), indicating that paternalistic leadership and job-related affective wellbeing are significant predictors of employee performance. However, with the addition of the interaction term the significance level remains same which signifies both models predicting significantly the relationship.

\begin{tabular}{llrc}
\multicolumn{5}{c}{$\begin{array}{c}\text { Table }-11 \\
\text { Coefficients }^{\mathrm{a}}\end{array}$} \\
\hline \multirow{3}{*}{ Model } & & \multicolumn{3}{c}{ Collinearity Statistics } \\
Tolerance & VIF \\
\hline 1 & Paternalistic_Leadership & .982 & 1.019 \\
& Job_Related_AW & .982 & 1.019 \\
\hline
\end{tabular}

a. Dependent Variable: Employees_Performance

Multicollinearity is the test of high intercorrelations among something like two self-governing elements in a various backslide model. When in doubt, multicollinearity can provoke more broad 
sureness extends that produce less strong probabilities to the extent the effect of free factors in a model. You can review multicollinearity by investigating obstruction and the Change Expanding Part (VIF) are two collinearity definite variables that can help you with perceiving multicollinearity. Strength is an extent of collinearity point by point by most quantifiable activities like SPSS; the variable s opposition is $1-\mathrm{R} 2$.

Conclusively, we can say that data is assembled through surveys, and then the gathered information is checked carefully to recognize any missing characteristics and further to avoid any abnormalities in responses of respondents. To perceive the missing characteristics, direct repeat runs are done to screen the data by using mean worth replacement procedure (Field). The apparent characteristics are a result of aversions made by respondents and included data that is under $1 \%$. Subsequently, thought to be immaterial to check the standard deviation (Little and Rubin, 2002). The missing characteristics are an immediate aftereffect of insignificant to different factors, met the essentials of data missing totally at sporadic (Little and Rubin, 2002). Statistical Package for the Social Sciences (SPSS) is used to take apart fragment estimations. Basically, association and backslide assessment are used to choose the association between paternalistic organization and occupation related passionate thriving on Laborers' presentation.

\section{Hypotheses Result}

\section{S.No. Hypotheses}

1. H1: There is a positive and significant impact of Paternalistic leadership Accept on employees' performance.

2.

H2: Job related affective wellbeing positively influences the relationship

Accept

of paternalistic leadership and employees' performance.

Results indicate that Paternalistic leadership maintains a significant relationship with Employee's performance. Similarly, Paternalistic leadership is also significantly related with Job related affective wellbeing. Furthermore, results show that all the three variables are positively and are significantly correlated with each other.

\section{CONCLUSION}

The current research study examines and explicates that how 'Paternalistic Leadership' an independent variable of the study affects 'Employees' Performance' a dependent variable of the study through a moderating variable 'Job related Affective Wellbeing'. We found through our research that 'Job related Affective Wellbeing' does moderate the association among paternalistic leadership and employees' performance. The vital impact to our work is based on a model that integrates and encompasses three acknowledged frameworks in the realm of management studies, current literature regarding leadership and employees' performance. However, there is a principal assumption that the role of paternalistic leadership is in the processes of identifications, so following research and further probing in to the information that paternalistic leadership styles do qualify and enhance the performance of the employees. Furthermore, following comprehensive research we find that to make the employees' performance better, the leaders must sponsor and endorse the job-related affective wellbeing of the employees. This research should augment further the values to the earlier works regarding paternalistic leadership.

Moreover, this has been reconnoitred that how paternalistic leadership impacts the performance of the employees by the moderation of job-related affective wellbeing. Earlier related works although depict the effect of paternalistic leadership on employees' performance but it has never been through the moderating role of job-related affective wellbeing. Conclusively speaking all the underlying factors affect the relationships amongst themselves. 


\section{RECOMMENDATIONS}

This research work also focused on leadership styles as paternalistic leadership and its impact on employees' performance, how job-related affective wellbeing moderate between paternalistic leadership and employee performance. There are many other factors excluded in this specific study and can be added in future research. The set of studies makes a major contribution as it varies from place to place. If we choose any other area or location of another different country, then findings of the study would be entirely different. This can be very useful study for those who have interest in the similar filed and utilize it for better results.

Based on the discussion above, following recommendations have been proposed for future researchers;

- More industries like telecom, engineering, manufacturing etc may be surveyed for the relationship of variables under study.

- More moderating variables may also be added to know the relationship between paternalistic leadership and employees' performance.

- This study is based on Islamabad and Rawalpindi region universities' middle level managers; thus area of the study may be broadened with other industries.

- Data from higher level managers may be collected for better understanding about the variables

REFERENCES

Alie, R.E., Beam, H., \& Carey, T.A. (1998). The use of teams in an undergraduate management program. Journal of Management Education, 22(6), 707-719.

Audrey, C.V., \& Patrice, R. (2012). Adaptive performance: A new scale to measure individual performance in organizations. Canadian Journal of Administrative Sciences, 29(2), 280293.

Austin, J.T., \& Villanova, P. (1992). The criterion problem: 1917-1992. Journal of Applied Psychology, 77(1), 836-874.

Baard, S.K., Rench, T.A., \& Kozlowski, S.W.J. (2014). Performance adaptation: A theoretical integration and review. Journal of Management, 40(2), 48-99.

Bateman, T.S., \& Organ, D.W. (1983). Job satisfaction and the good soldier: The relationship between affect and employee "citizenship." Academy of Management Journal, 26(1), 587595.

Bateman, T.S., \& Snell, S.A. (2007). Management: Leading \& collaborating in a competitive world. Boston: McGraw-Hill.

Bergeron, D.M. (2007). The potential paradox of organizational citizenship behavior: Good citizens at what cost? Academy of Management Review, 32(4), 1078-1096.

Bommer, W.H., Johnson, J.L., Rich, G.A., Podsakoff, P.M., \& MacKenzie, S.B. (1995). On the interchange ability of objective and subjective measures of employee performance. Personnel Psychology, 48(1), 587-605.

Bonner, S.E., Hastie, R., Young, S.M., Hesford, J., \& Gigone, D. (2001). Effects of monetary incentives on the performance of a cognitive task: The moderating role of skill. (Working Paper). University of Southern California. Los Angeles, California.

Borman, W.C., \& Brush, D.H. (1993). More progress toward a taxonomy of managerial performance requirements. Human Performance, 6(1), 1-21., vol. 3, no. 10.

Borman, W.C., \& Motowidlo, S.J. (1993). Expanding the criterion domain to include elements of contextual performance. In N. Schmitt \& W. Borman (Eds), Personnel selection in organizations (pp. 71-98). New York: Jossey-Bass

(1997). Task performance and contextual performance: The meaning for personnel selection research. Human Performance, 10(2), 99-109.

Borman, W.C., Buck, D.E., Hanson, M.A., Motowidlo, S.J., Stark, S., \& Drasgow, F. (2001). An examination of the comparative reliability, validity, and accuracy of performance ratings made using computerized adaptive rating scales. Journal of Applied Psychology, 86(2), 965-973.

Boyt, T., Lusch, R.F., \& Naylor, G. (2001). The role of professionalism in determining job satisfaction in professional services: A study of marketing researchers. Journal of Service Research, 3(4), 321-330. 
Brief, A.P., \& Motowidlo, S.J. (1986). Prosocial organizational behaviors. Academy of Management Review, 11(1), 710-725.

Camerer, C.F., \& Hogarth, R.M. (1999). The effects of financial incentives in experiments: A review and capitallabor-production framework. Journal of Risk and Uncertainty, 19(4), 7-42.

Campbell, J.P. (1990). Modeling the performance prediction problem in industrial and organizational psychology. In M.D. Dunnette \& L.M. Hough (Eds), Handbook of industrial and organizational psychology (pp. 687-732).

Palo Alto, CA: Consulting Psychologists Press. Campbell, J.P., McCloy, R.A., Oppler, S.H., \& Sager, C.E. (1993). A theory of performance. In C.W. Schmitt \& W.C.A. Borman (Eds), Personnel selection in organizations (pp. 35-70).

San Francisco, CA: Jossey Bass. Cohen, S.G., \& Bailey, D.E. (1999). What makes teams work: Group effectiveness research from the shop floor to the executive suite. Journal of Management, 23(3), 239- 290.

Coleman, V.I., \& Borman, W.C. (2000). Investigating the underlying structure of the citizenship performance domain. Human Resource Management Review, 10(2), 24-44.

Conway, J.M. (1999). Distinguishing contextual performance from task performance for managerial jobs. Journal of Applied Psychology, 84(3), 3-13.

Costello, A.B., \& Osborne, J.W. (2005). Best practices in exploratory factor analysis: Four recommendations for getting the most from your analysis. Practical Assessment. Research \& Evaluation, 10(2), 1-9.

De Vellis, R. (2003). Scale development: Theory and applications (2nd ed.). Thousand Oaks, CA: SAGE Publications.

Fabrigar, L.R., Wegener, D.T., MacCallum, R.C., \& Strahan, E.J. (1999). Evaluating the use of exploratory factor analysis in psychological research. Psychological Methods, 4(3), 272299.

Fay, D., \& Luhrmann, H. (2004). Current themes in organizational change. European Journal of Work and Organizational Psychology, 13(2), 113-119.

Frese, M., \& Fay, D. (2001). Personal initiative: An active performance concept for work in the 21st century. In B.M. Staw \& R.L. Sutton (Eds), Research in organizational behavior (pp. 133187).

Greenwich, CT: JAI Press. Friedman, D., \& Sunder, S. (1994). Experimental methods: A primer for economists. New York: Cambridge University Press.

Fried, Y., Levi, A.S., \& Laurence, G. (2008). Motivation and job design in the new world of work. In C. Cooper \& C. Cartwright (Eds), The Oxford handbook of personnel psychology (pp. 586-611). Oxford: Oxford University Press.

Gerbing, D.W., \& Anderson, J.C. (1993). Monte Carlo evaluations of goodness-of-fit indices for structural equation models. In K.A. Bollen \& J.S. Long (Eds), Testing structural equation models (pp. 40-65). CA: SAGE Publications Inc.

(1988). An updated paradigm for scale development incorporating unidimensionality and its assessment. Journal of Marketing Research, 25(2), 186-192.

Griffin, M., Parker, S., \& Mason, C. (2010). Leader vision and the development of adaptive and proactive performance: A longitudinal study. Journal of Applied Psychology, 95(3), 174-182.

Griffin, M.A., Neal, A., \& Parker, S.K. (2007). A new model of work role performance: Positive behavior in uncertain and interdependent contexts. Academy of Management Journal, 50(2), 327-347.

Gupta, N., \& Shaw, J.D. (2014). Employee compensation: The neglected area of HRM research. Human Resource Management Review, 24(1), 1-4.

Guadagnoli, E., \& Velicer, W.F. (1988). Relation of sample size to the stability of component patterns. Psychological Bulletin, 103(1), 265-275.

Hair, J., Black, W., Babin, B., \& Anderson, R. (2010). Multivariate data analysis (7th ed.). Upper Saddle River, NJ: Prentice-Hall Inc.

Hair, J., Black, W., Babin, B., Anderson, R., \& Tatham, R. (2006). Multivariate data analysis (6th ed.). Uppersaddle River, NJ: Pearson Prentice Hall. 